\title{
Fatal Cerebral Air Embolism following Uneventful Flexible Bronchoscopy
}

\author{
Andrea Azzola ${ }^{a}$ Christophe von Garnier ${ }^{a, c}$ Prashant N. Chhajed ${ }^{a} \quad$ Udo Schirp $^{\mathrm{b}}$ Michael Tamm ${ }^{\mathrm{a}}$ \\ ${ }^{a}$ Clinic of Pulmonary Medicine, and ${ }^{b}$ Department of Radiology, University Hospital Basel, Basel, and \\ 'Respiratory Medicine, Bern University Hospital, Bern, Switzerland
}

\section{Established Facts}

- Flexible bronchoscopy is a frequently used and safe procedure with reported rates of mortality, major complications, and minor complications of $0.1,1.7$, and $6.5 \%$, respectively.

- Cerebral embolism following transbronchial needle aspiration and/or transbronchial biopsy is an exceedingly rare complication of unknown frequency.

\section{Novel Insights}

- We herein report 2 cases of seemingly uneventful bronchoscopies that resulted in fatal cerebral air embolism.

- Although this complication occurred with a frequency of $<0.02 \%$ in our institution, every bronchoscopist should recognize this severe adverse event in order to initiate prompt supportive measures and consider hyperbaric oxygen therapy.

\section{Key Words}

Air embolism • Bronchoscopy • Complications •

Transbronchial biopsy · Transbronchial needle aspiration

\section{Abstract}

Flexible bronchoscopy is a widely used and safe procedure with a reported maximal mortality rate of $0.04 \%$ and a majorcomplications rate of $0.5 \%$. There are, however, only few case descriptions for postinterventional cerebral air embolism and the frequency of this supposedly rare complication is unknown. The current study presents 2 patients with nonsmall cell lung cancer who suffered fatal cerebral air embolism following diagnostic bronchoscopy with transbronchial needle aspiration and transbronchial biopsy, resulting in a frequency of $<0.02 \%$ for this severe complication in our institution. In addition to early supportive measures, 1 patient received hyperbaric oxygen therapy as further treatment. Prompt recognition of this complication is mandatory in order to implement appropriate supportive measures. Highflow oxygen should be administered and hyperbaric oxygen therapy may be considered, if available. If possible, positive pressure ventilation should be avoided.

Copyright $\odot 2010$ S. Karger AG, Basel

\section{KARGER}

Fax +4161306 1234

E-Mail karger@karger.ch

www.karger.com (c) 2010 S. Karger AG, Basel

0025-7931/10/0806-0569\$26.00/0

Accessible online at:

www.karger.com/res
Prashant N. Chhajed, MD

Clinic of Pulmonary Medicine, University Hospital Basel

Petersgraben 4

$\mathrm{CH}-4031$ Basel (Switzerland)

Tel. +41 6126551 84, Fax +41 6126545 87, E-Mail pchhajed@uhbs.ch 

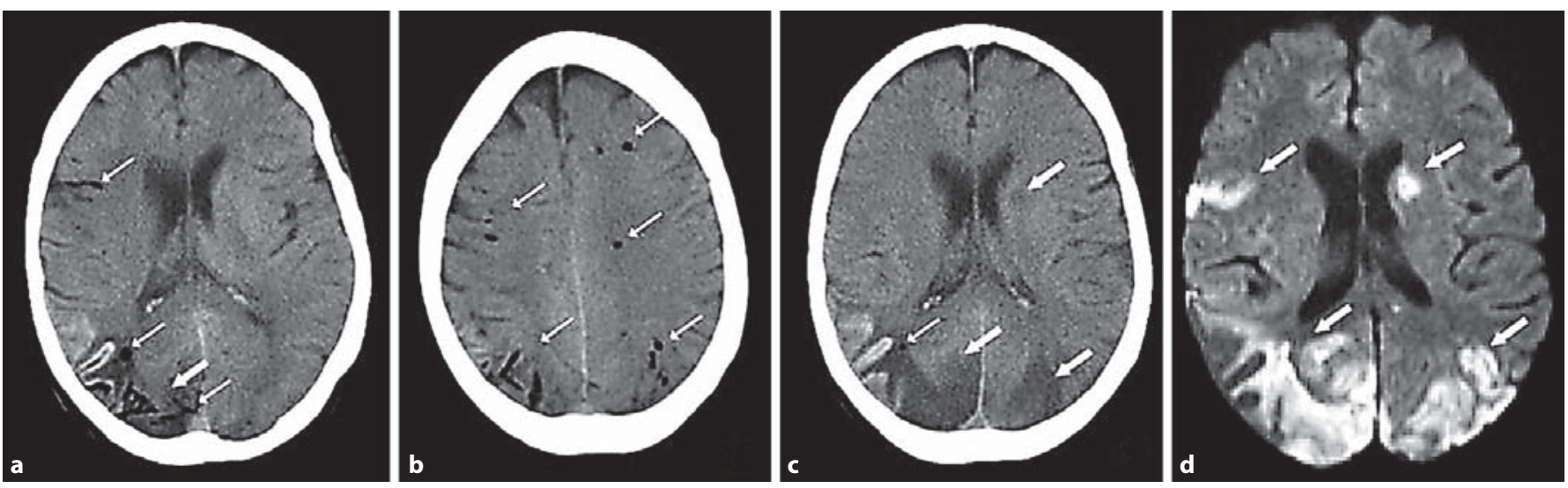

Fig. 1. The cerebral CT scan following bronchoscopy demonstrates multifocal cerebral air embolism in both hemispheres (a, b, thin arrows) and the beginning of ischemia in the right occipital area (a, thick arrow). A follow-up CT scan 1 day later reveals extensive new ischemic lesions bilaterally in the occipital region and left capsula interna (c, thick arrows) and few air lesions in the right occipital region (c, thin arrow). A diffusionweighted MRI sequence 5 days later shows extensive multifocal ischemic lesions (d, thick arrows).

\section{Introduction}

Flexible bronchoscopy is widely used with reported mortality rates ranging from 0 to $0.04 \%$ and major-complications rates of $0.01-0.7 \%$ [1-3]. The 1991 survey of the American College of Chest Physicians reported a minorcomplications rate of up to $10 \%$ and a major-complications rate of up to 5\% [4]. In a prospective trial of 908 patients, Pereira et al. [5] reported mortality in $0.1 \%$, major complications in $1.7 \%$, and minor complications in $6.5 \%$ of the procedures. Major complications included cardiorespiratory arrest, respiratory depression, pneumothorax, pulmonary edema, pneumonia, and airway obstruction [6]. Minor complications were vasovagal reactions, fever, cardiac arrhythmias, hemorrhage, airway obstruction, pneumothorax, aphonia, psychotic reactions, nausea, and vomiting [5]. In a retrospective study of 23,682 patients, Faguand et al. [1] reported a mortality rate of $0.013 \%$ and a major-complications rate of $0.637 \%$ (i.e. laryngotracheal or bronchial spasm, massive hemoptysis, arrhythmia, airway obstruction, pneumothorax, esophagotracheal fistula, tracheal perforation, or death). Cerebral air embolism following bronchoscopy or CT-guided biopsy has been only anecdotally reported in the literature and to the best of our knowledge has not been systematically reported in larger trials $[6,7]$. The paucity of such reports might reflect the rarity of this severe adverse event or underdiagnosis or underreporting, respectively.

\section{Case Report}

Case 1

A 60-year-old female patient was admitted to hospital because of aphasia and a lung infiltrate on the chest X-ray suggestive of lung cancer. Cerebral MRI revealed multiple small cerebral thromboembolic lesions. A thoracic CT scan showed a peripheral nodule and mediastinal lymphadenopathy. Flexible bronchoscopy was performed under conscious sedation with $5 \mathrm{mg}$ midazolam and $5 \mathrm{mg}$ hydrocodone. Transbronchial needle aspiration (TBNA) of the mediastinal lymph nodes was performed first, followed by brush cytology and TBNA and transbronchial biopsy (TBB) of the nodule in the left upper lobe under fluoroscopic guidance. The total duration of bronchoscopy was $30 \mathrm{~min}$. Following the completion of bronchoscopy, the patient remained unresponsive even after the reversal of sedation with flumazenil and naloxone. Blood pressure, heart rate, and oxygen saturation remained stable throughout the procedure and thereafter, with no indication for ventilatory support. Breath sounds were symmetrical. The neurological examination revealed a Glasgow Coma Score (GCS) of 7/15 points, pupils were equal and reactive to light, and no new focal neurological signs were apparent. There were no endobronchial abnormalities. Relevant endobronchial bleeding or obstruction was excluded with a short rebronchoscopy. Arterial blood gases under 2 liters/min oxygen via a facial mask showed mild hypoxemia with a partial pressure of oxygen $\left(\mathrm{PO}_{2}\right)$ of $68 \mathrm{~mm} \mathrm{Hg}(9.1 \mathrm{kPa})$ and a partial pressure of carbon dioxide $\left(\mathrm{PCO}_{2}\right)$ of $39 \mathrm{~mm} \mathrm{Hg}$ $(5.2 \mathrm{kPa})$. Hypoglycemia was excluded and fluoroscopy did not show a pneumothorax. A brain CT scan showed bihemispheric extensive cerebral air embolism (fig. 1a, b). Hyperbaric oxygen therapy was initiated within $3 \mathrm{~h}$ after bronchoscopy. A repeat CT scan $12 \mathrm{~h}$ after hyperbaric oxygen therapy showed minimal residual air but extensive new ischemic lesions (fig. 1c, d). Despite 3 hyperbaric oxygen therapy sessions only minor neurological recovery occurred. Cytological and histological results of bronchoscopy confirmed inoperable non-small cell lung cancer (NSCLC; 

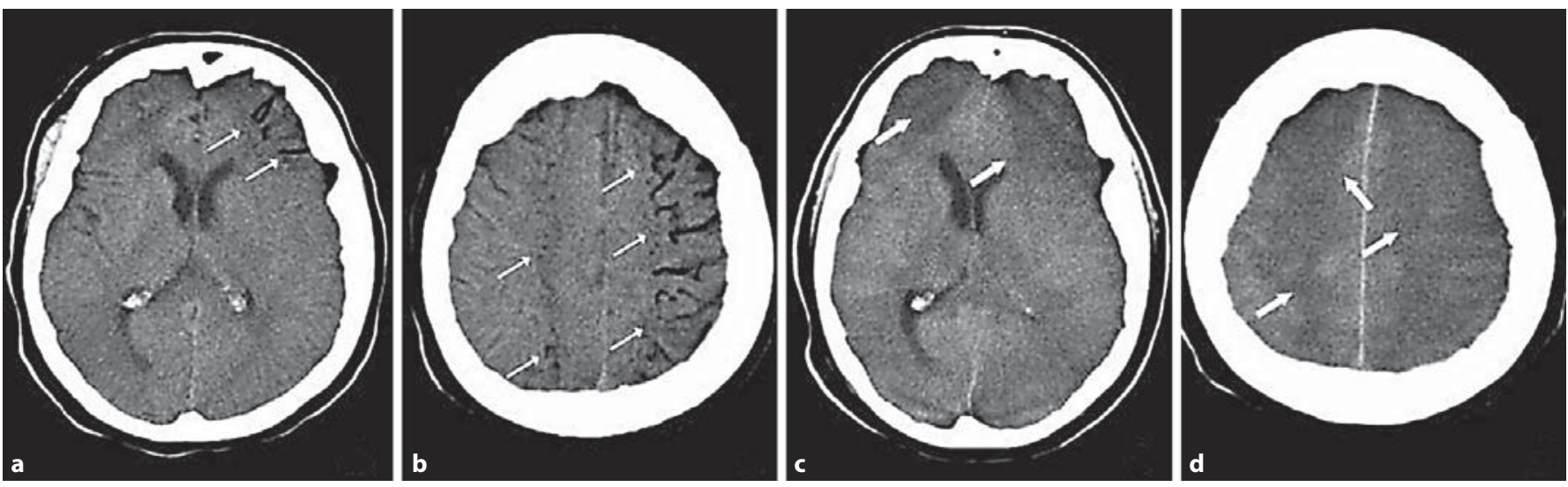

Fig. 2. The cerebral CT scan following bronchoscopy demonstrates multifocal cerebral air embolism (a, b, thin arrows). Corresponding slices of the follow-up CT scan $12 \mathrm{~h}$ later show no residual air lesions but extensive hypodense areas representing ischemia (c, $\mathbf{d}$, thick arrows) and diffuse brain edema.

cT2 $\mathrm{pN} 3 \mathrm{cMx}$, stage IIIB). Despite therapeutic anticoagulation with intravenous heparin, progressive deep venous thrombosis of the lower limbs and pulmonary embolism were diagnosed. The likely explanation for the ongoing thromboembolic events was severe paraneoplastic thrombophilia. Heparin-induced thrombocytopenia developed and was treated with the cessation of heparin and the induction of anticoagulation with lepirudin. Critical ischemia of the left foot developed despite anticoagulation. In the setting of an inoperable carcinoma with severe paraneoplastic complications and extensive neurological impairment following air embolism and after discussion with the patient's relatives palliative care was provided and the patient died few days later.

\section{Case 2}

A 68-year-old female patient presented with a new 2-cm nodule in the superior segment of the right lower lobe without mediastinal adenopathy. Two years prior, she had undergone a right upper lobectomy for NSCLC stage IIA (pT1 pN1 cM0). The new nodule was highly suspicious for lung cancer. Flexible bronchoscopy was performed under intravenous sedation with $5 \mathrm{mg}$ hydrocodone and $140 \mathrm{mg}$ propofol. Brush cytology and TBNA were performed using fluoroscopy guidance. Only minor local bleeding occurred. Four minutes after the procedure the patient manifested hypotension, tachycardia, and oxygen desaturation. Intravenous ephedrine $5 \mathrm{mg}$ and i.v. atropine $0.5 \mathrm{mg}$ were administered along with increased oxygen supplementation via a facial mask. The hemodynamic parameters and oxygen saturation rapidly improved. Naloxone was administered but the patient continued to remain unresponsive. Breath sounds were symmetrical. Blood pressure, heart rate, and oxygen saturation had been stable during bronchoscopy. Blood pressure decreased to $70 / 40 \mathrm{~mm} \mathrm{Hg} 4 \mathrm{~min}$ after bronchoscopy, heart rate increased to $125 \mathrm{bpm}$, and oxygen saturation dropped to $70 \%$. Within $5 \mathrm{~min}$ after the institution of emergency measures, hemodynamic stabilization was achieved without ventilatory assistance (blood pressure $110 / 60 \mathrm{~mm} \mathrm{Hg}$, heart rate $110 \mathrm{bpm}$, and oxygen saturation 88\%). Neurological examination revealed a GCS of 4/15 points, and pupils were anisocoric (the left pupil was larger than the right) but reactive to light. No other focal neurological signs were present. Arterial blood gases under 10 liters/min oxygen via a facial mask showed a $\mathrm{PO}_{2}$ of $60 \mathrm{~mm} \mathrm{Hg}(8.0$ $\mathrm{kPa})$ and $\mathrm{a} \mathrm{PCO}_{2}$ of $49.5 \mathrm{~mm} \mathrm{Hg}(6.6 \mathrm{kPa})$. Fluoroscopy was performed to exclude a pneumothorax. The patient was intubated due to persisting coma. Repeat bronchoscopy showed minor residual blood clots in the superior segment of the right lower lobe but no active endobronchial bleeding. A brain CT scan revealed extensive cerebral air embolism of the left hemisphere (fig. 2a, b). Because of further neurological worsening (fixed mydriasis and the partial disappearance of brainstem reflexes) and significant comorbidities (high suspicion of recurrent NSCLC, severe COPD, coronary artery disease, and aneurysm of the descending aorta) no hyperbaric oxygen therapy was initiated. A follow-up brain CT scan showed diffuse brain edema (fig. 2c, d) and the patient passed away $19 \mathrm{~h}$ after the cerebral air embolism had occurred.

\section{Discussion}

Both patients in the current study developed cerebral air embolism following uneventful bronchoscopy with TBNA and TBB performed to diagnose lung cancer. TBNA is typically performed for small pulmonary nodules and mediastinal lymphadenopathy. In our institution 11,245 flexible bronchoscopies have been conducted in the last 10 years and TBB and TBNA are routinely performed. We have observed 2 cases of cerebral air embolism during this period, resulting in an overall incidence of $<0.02 \%$. In both cases, flexible bronchoscopy was performed by experienced pulmonologists under standard conditions and in the semirecumbent position. There were no other complications such as major bleeding, pneumothorax, or excessive coughing. Cerebral air embolism has been reported following TBB in a patient with pulmonary amyloidosis in 
which hemorrhage after biopsy required endotracheal intubation and positive pressure ventilation [7]. Postmortem findings in this publication suggested that bleeding and air embolism were related to persistent patency of the involved vessels following biopsy. Moreover, there is increasing evidence of gas embolization occurring with the utilization of argon plasma coagulation, as was experimentally confirmed by Feller-Kopman et al. [8] in an animal model. The exact mechanism is unclear at present, but it has been suggested that small airway-venous fistulas are created through which positive pressure or jet ventilation may force air into the vasculature [8-11].

In general, the early diagnosis of cerebral air embolism is mandatory in order to initiate prompt supportive treatment including hyperbaric oxygen therapy [12]. Although this complication is very rare, respiratory physicians should consider this possibility in patients who remain nonresponsive after bronchoscopy. Following diagnosis with an immediate CT scan, emergency measures for suspected cerebral air embolism include airway management, high-flow oxygen supplementation, bleeding control, and circulatory support. If possible, positive pressure ventilation should be avoided. If emergency intubation is needed, ventilatory pressures should be kept as low as possible and positive end-expiratory pressure avoided. Additionally, in animal experiments hyperbaric treatment after cerebral air embolism had a beneficial effect on intracranial pressure, brain oxygenation, and brain glucose metabolism [13]. Though no reports of randomized controlled trials in humans exist, early hyperbaric oxygen therapy is recommended for cerebral air embolism of any origin (decompression sickness or iatrogenic after diagnostic or therapeutic medical interventions). We believe that hyperbaric therapy may help reduce longterm neurologic impairments after iatrogenic cerebral air embolisms of any cause, including air embolism following bronchoscopy. Therefore, if available, we suggest considering this therapeutic option without delay. However, due to the complication's rarity, the availability of hyperbaric chambers cannot be systematically requested for centers performing bronchoscopies.

\section{Conclusion}

Cerebral air embolism following TBB or TBNA is a very rare complication. The bronchoscopist should include cerebral air embolism in the differential diagnosis when a patient remains unresponsive or presents with neurological signs following bronchoscopy. Prompt recognition of this complication is mandatory in order to initiate early supportive measures. If available, we suggest considering early hyperbaric oxygen therapy after cerebral air embolism following bronchoscopic intervention.

\section{Financial Disclosure and Conflicts of Interest}

The authors have nothing to disclose.

\section{References}

1 Faguang J, Deguang M, Dongling C, Enqing F, Yonghong X, Tonggang L: Severe complications of bronchoscopy. Respiration 2008; 76:429-433.

2 Pue CA, Pacht ER: Complications of fiberoptic bronchoscopy at a university hospital. Chest 1995; 107:430-432.

-3 Simpson FG, Arnold AG, Purvis A, Belfield PW, Muers MF, Cooke NJ: Postal survey of bronchoscopic practice by physicians in the United Kingdom. Thorax 1986;41:311-317.

4 Prakash UB, Offord KP, Stubbs SE: Bronchoscopy in North America: the ACCP survey. Chest 1991;100:1668-1675.

$\checkmark 5$ Pereira W Jr, Kovnat DM, Snider GL: A prospective cooperative study of complications following flexible fiberoptic bronchoscopy. Chest 1978;73:813-816.
6 Erickson AD, Irwin RS, Teplitz C, Corrao WM, Tarpey JT: Cerebral air embolism complicating transbronchoscopic lung biopsy. Ann Intern Med 1979;90:937-938.

-7 Strange C, Heffner JE, Collins BS, Brown FM, Sahn SA: Pulmonary hemorrhage and air embolism complicating transbronchial biopsy in pulmonary amyloidosis. Chest 1987;92:367-369.

8 Feller-Kopman D, Lukanich JM, Shapira G, Kolodny U, Schori B, Edenfield H, Temelkuran B, Ernst A, Schindel Y, Fink Y, Fox J, Bueno R: Gas flow during bronchoscopic ablation therapy causes gas emboli to the heart: a comparative animal study. Chest 2008; 133:892-896

-9 Goldman Y, Panzica PJ, Pinto DS, Delatorre R, Feller-Kopman D, Ernst A: Cardiac arrest due to left ventricular gas embolism after bronchoscopic argon plasma coagulation: a case report. J Bronchol 2007;14:33-35.
10 Golish JA, Pena CM, Mehta AC: Massive air embolism complicating Nd-YAG laser endobronchial photoresection. Lasers Surg Med 1992;12:338-342.

-11 Reddy C, Majid A, Michaud G, Feller-Kopman D, Eberhardt R, Herth F, Ernst A: Gas embolism following bronchoscopic argon plasma coagulation: a case series. Chest 2008;134:1066-1069.

12 Blanc P, Boussuges A, Henriette K, Sainty JM, Deleflie M: Iatrogenic cerebral air embolism: importance of an early hyperbaric oxygenation. Intensive Care Med 2002;28:559563.

13 van Hulst RA, Drenthen J, Haitsma JJ, Lameris TW, Visser GH, Klein J, Lachmann B: Effects of hyperbaric treatment in cerebral air embolism on intracranial pressure, brain oxygenation, and brain glucose metabolism in the pig. Crit Care Med 2005;33:841-846. 